\title{
Choroid Plexus Papilloma of the Fourth Ventricle: A Pediatric Patient
}

\begin{abstract}
Choroid plexus papilloma is a low-frequency entity in both the adult and pediatric populations. Its clinical presentation is very variable as it depends on its location and length. We must always do the differential diagnosis between papilloma and other intraventricular pathologies. This article is about a case report of a pediatric patient with a Choroid plexus papilloma located in the fourth ventricle, a location that is atypical for the pediatric population.
\end{abstract}

Keywords: Choroid plexus papilloma, fourth ventricle, pediatric

\section{Introduction}

Choroid plexus papilloma constitutes from $0.4 \%$ to $1 \%$ of all intracranial tumors, and in children, they rise from $1.5 \%$ to $6 \%{ }^{[1]}$ Choroid plexus papilloma is localized in adults usually infratentorial, and about $70 \%$ can be found in the fourth ventricle, whereas in the pediatric population the most common site is supratentorial and located in the lateral ventricles. ${ }^{[2]}$ Although it can appear at any age, $70 \%$ of the cases have been reported in patients younger than 2 years old, ${ }^{[1,3,4]}$ extraventricular locations have also been described. ${ }^{[3,5,6]}$

In this report, we describe a rare case of choroid plexus papilloma located in the fourth ventricle, in a pediatric patient.

\section{Case Report}

A 13 year old female patient is referred to an emergency service with a mostly bilateral retroocular headache after 2 years of evolution. the pain increased in frequency and intensity for two months which caused the patient to woke up in the mornings. Due to this, in the remission site, a cranial computed tomography (CT) scan was performed. It showed an infratentorial lesion, so the initial emergency service physician sends us the clinical record and the patient for integral management. When the patient came, a cranial nuclear magnetic resonance imaging (MRI) was performed [Figures 1-3].

\footnotetext{
This is an open access journal, and articles are distributed under the terms of the Creative Commons Attribution-NonCommercialShareAlike 4.0 License, which allows others to remix, tweak, and build upon the work non-commercially, as long as appropriate credit is given and the new creations are licensed under the identical terms.
}

For reprints contact: reprints@medknow.com
A large infratentorial mass with robust enhancement, heterogeneous dilation of the lateral ventricles, and other signs of hydrocephalus such as horizontalization of the temporal horns was found. Taking into account the patient's findings and symptoms, it was considered necessary to perform a tumor resection through occipital craniectomy. During the procedure, we did not have any complications [Figure 4]. Furthermore, considering the high risk of hydrocephalus, we performed a system of the fifth ventricle. The patient was sent to the pediatric intensive care unit.

The outcome of the $1^{\text {st }}$ day became torpid, with a high rate of production of xanthochromic cerebrospinal fluid (CSF), for which it was considered necessary to perform a ventriculoperitoneal shunt.

After several days of satisfactory evolution, the patient became drowsy again, for that reason it was considered necessary to perform a new cranial CT scan [Figure 5], in which significant ventricular dilatation was evidenced. With a diagnosis of hydrocephalus due to shunt failure, the patient was taken back to surgery.

In the surgery, it was found a high quantity of detritus in the porosities of the proximal catheter shunt, so a review of its functionality and a cleaning was performed. Two hours after the procedure, the patient was awake without neurological deficit. A control CT scan was performed on the $3^{\text {rd }}$ day [Figure 6].

Fifteen days postoperatively, the pathology reported choroid plexus papilloma, and after a

\footnotetext{
How to cite this article: Muñoz Montoya JE, Maldonado Moran MA, Santamaría Rodríguez P, Toro Lopez S, Perez Cataño CS, Luque Suarez JC. Choroid plexus papilloma of the fourth ventricle: $A$ pediatric patient. Asian J Neurosurg 2019;14:585-8.
}

\section{Juan Esteban \\ Muñoz Montoya ${ }^{1}$, Miguel Angel Maldonado Moran', Paula Santamaria Rodriguez ${ }^{2}$, Sebastian Toro Lopez', Carlos Sayith Perez Cataño ${ }^{1}$, Juan Carlos Luque Suarez ${ }^{3}$}

${ }^{1}$ Departament of Neurosurgery, Universidad Militar Nueva Granada, ${ }^{2}$ Medicine Faculty, Universidad del Rosario,

${ }^{3}$ Neurosurgeon, Departament of Neurosurgery, Universidad Militar Nueva Granada, Hospital Militar Central, Bogotá, Colombia

Address for correspondence: Dr. Juan Esteban Muñoz Montoya,

Universidad Militar Nueva Granada, Bogotá, Colombia. E-mail: juanesteban1285@ gmail.com

Access this article online Website: www.asianjns.org DOI: 10.4103/ajns.AJNS_301_18 Quick Response Code:

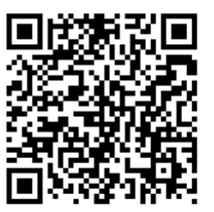




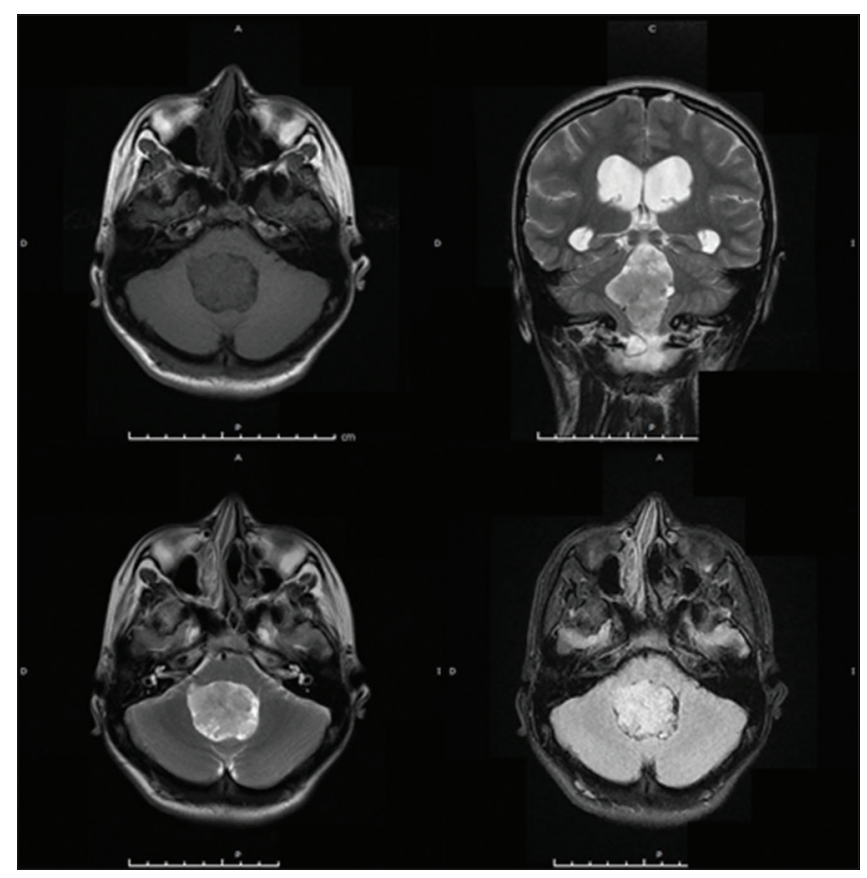

Figure 1: Simple magnetic resonance image, sequences weighted in T1 axial cut. Intraventricular mass hypointense. Coronal and axial cut T2: hyperintense lesion with irregular edges. The fluid-attenuated image recovery in which can observe that lesion has signal intensity relatively greater than the parenchyma

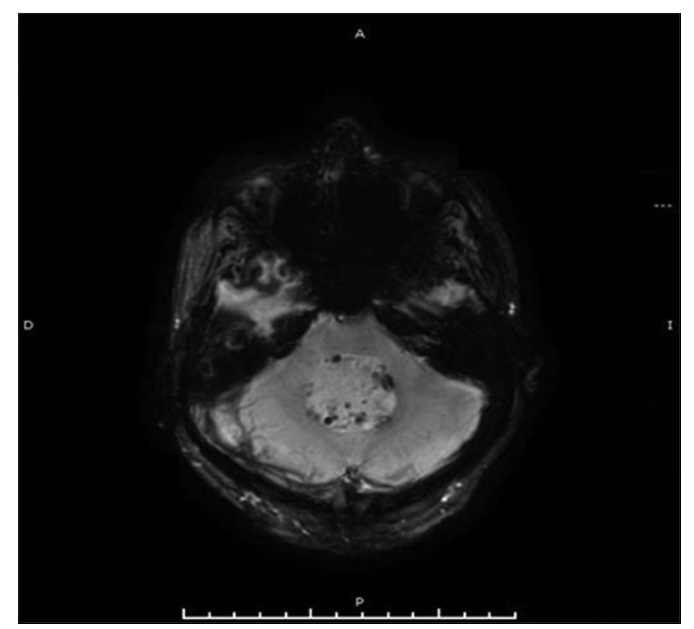

Figure 3: Susceptibility-weighted magnetic resonance sequences in which can observe multiple foci of small hemorrhages in the periphery of the lesion

follow-up at 3 months, 6 months, and a year later, the patient did not present any clinical deterioration or complication.

\section{Discussion}

Choroid plexus papilloma is the most frequent ventricular tumor, but it is not common in the third ventricle and cerebellopontine angle. In pediatric population, $80 \%$ of this kind of tumor can be found in the lateral ventricles, $16 \%$ in the fourth ventricle, and $4 \%$ in the third ventricle. ${ }^{[7-9]}$ Just a few cases of choroid plexus papilloma of the fourth ventricle in pediatric patients have been reported, with an approximated incidence of $10 \%-20 \% .^{[2,10]}$

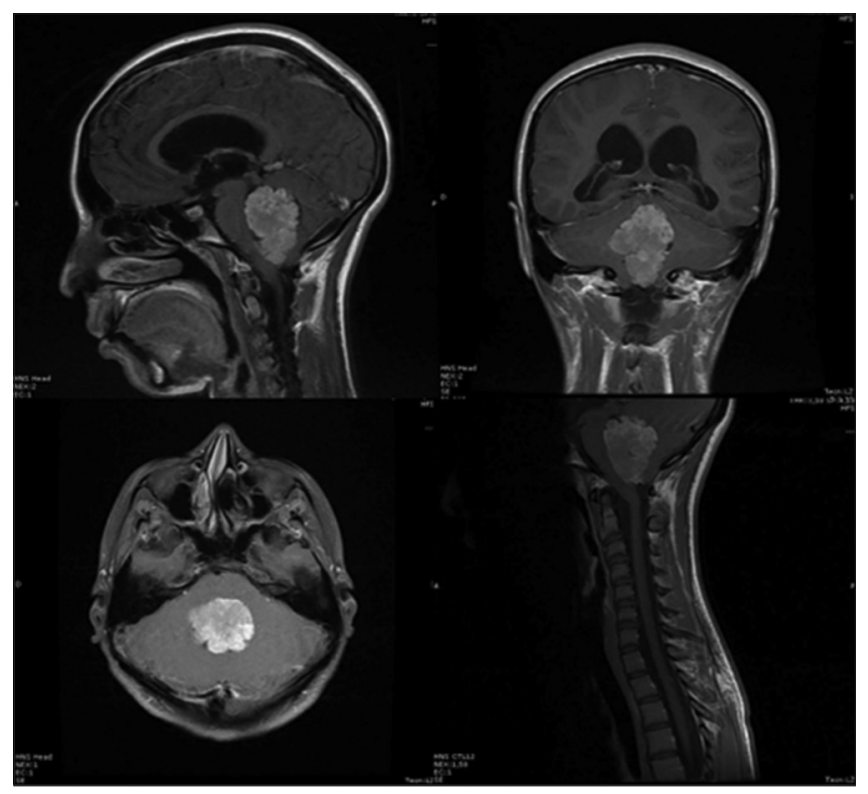

Figure 2: Magnetic resonance image sequence T1 contrasted with all patient cuts

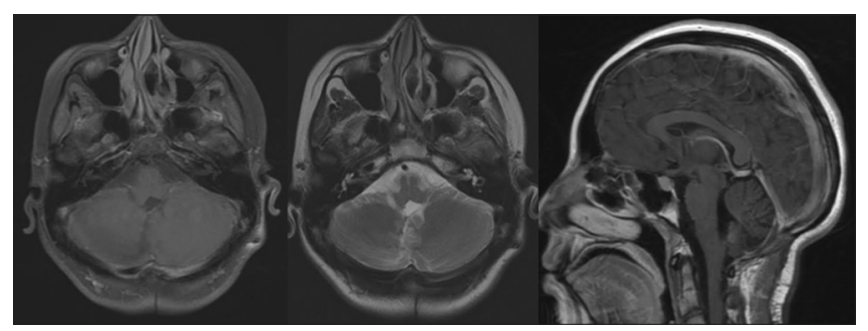

Figure 4: Simple and contrast magnetic resonance image, sequences weighted in T1 axial cut, T2 axial cut, and sequences contrast sagittal where no tumor residue is identified in the posterior fossa

Choroid plexus papilloma is benign in $80 \%$ of the cases and have a good prognosis. The World Health Organization classification includes: (i) low grade, (ii) atypical, (iii) carcinoma. ${ }^{[1]]}$ The choroid plexus papilloma shows an annual incidence of $0.3 / 1,000,000$ people, with a male-to-female ratio of 1.2:1. ${ }^{[12]}$ Furthermore, it is more frequent in the $1^{\text {st }}$ year of life, being the $10 \%-20 \%$ of the brain tumors at this age, with the mean of time for its diagnosis of 3.5 years. ${ }^{[13]}$

As mentioned before, in the pediatric population, this kind of tumors are usually found in the lateral ventricles, more frequent in the left ventricle, ${ }^{[12]}$ and it has been reported a mean diagnosis age that varies with the localization of the tumor; 1.5 years for lateral and third ventricle, 22.5 years for fourth ventricle, and 35.5 years for cerebellopontine angle. ${ }^{[12]}$

The clinical manifestations of this entity, as any other central nervous system tumor, change in function of the location. Usually, the patient with a choroid plexus papilloma of the posterior fossa can have gait disturbance, dizziness, papilledema, cranial nerves palsy, convulsions, hydrocephalus, and retardation of the psychomotor 


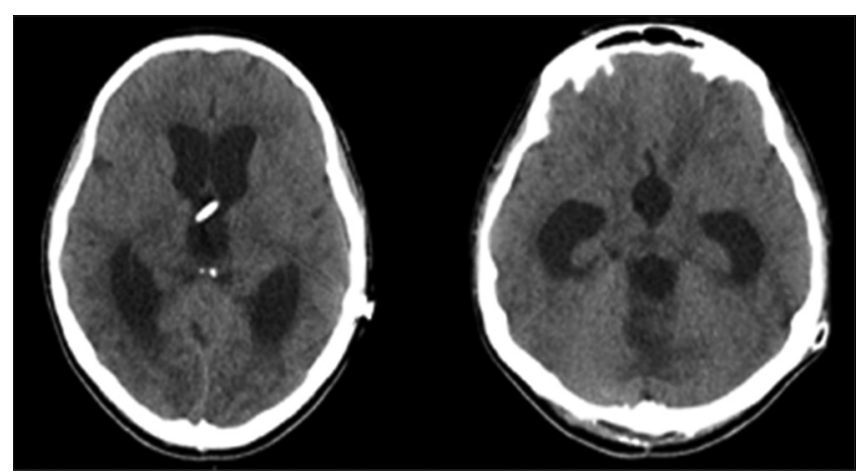

Figure 5: Emergency cranial computed tomography scan: dilatation of the lateral ventricles, horizontalization of temporal horns, and bulging of the third ventricle

functions. ${ }^{[13,14]}$ However, in this kind of tumor, the symptoms are directly linked to hydrocephalus, that develops due to overproduction of CSF by the tumor cells, obstruction of the ventricular system, or by resorption dysfunction. ${ }^{[13,14]}$

Differential diagnosis of the intraventricular tumors in children includes wide giant subependymal astrocytoma, low-grade astrocytoma, meningiomas, ependymomas, medulloblastomas, metastases, and colloid cysts, between others. However, it is also important to consider other possible differential diagnoses, such as physiological enlargement of the choroid plexuses and xanthogranulomas of the choroid plexuses. ${ }^{[15,16]}$ Some cases have been reported in siblings and in association with Li-Fraumeni, Aicardi, and Von Hippel-Lindau syndromes. ${ }^{[13,17]}$

The choroid plexus papilloma in MRI has an hyperdense or isodense signal, and it could have calcifications in $25 \%$ of the cases. ${ }^{[12,18]}$ Hydrocephalus can be also found. In the MRI, this entity appears as a "cauliflower," with vascularization, contrast-enhanced lesion, is rare but it could have a cystic form too. ${ }^{[18]}$ In the T1 sequence, they appear well defined, isodense, or hypointense, whereas in the T2-weighted sequence, it is observed as an isodense or hyperintense signal. Whenever we perform the imaging evaluation of these patients, it is necessary to rule out dissemination by $\mathrm{CSF}^{[15]}$ and a complete central nervous system study has to be made.

Spectroscopy is also very useful. This kind of tumor is described as low or none N-Methyl D-Aspartate, small peaks of choline and lactate, and elevation of myoinositol, which will help us to distinguish it from the carcinoma of choroid plexuses ${ }^{[15]}$ the carcinoma has a lower survival rate and requires adjuvant treatment with chemotherapy and sometimes radiotherapy. ${ }^{[19,20]}$

Other neuroimaging tools include angiography, which is useful for preoperative planning and visualization of the vascular supply for the tumor, as we mentioned before, choroid plexus papilloma has good vascularization, and the main mortality in the procedures is bleeding. ${ }^{[13,21]}$

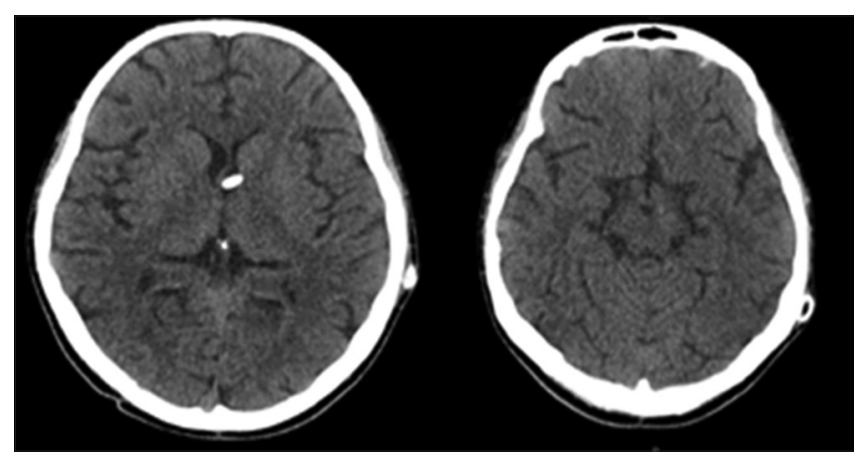

Figure 6: Postoperative control computed tomography scan: ventriculoperitoneal shunt in place. Normal ventricular size

Preoperative embolization should be considered too, but the small vessels of the tumor may not be reachable. ${ }^{[21,22]}$

Surgical resection of the tumor is the cornerstone of the treatment, but hydrocephalus management highly important and is an open topic of discussion. Some surgeons/authors report that the hydrocephalus should be resolved before the tumor resection with an external ventricular drain, and after the resection, it could be retired without any other management. ${ }^{[23-25]}$ Meanwhile, other authors say that is safer to put a ventriculoperitoneal shunt intraoperative, as some hydrocephalus symptoms may not resolve after tumor resection due to the possible development of CSF resorption dysfunction. ${ }^{[26]}$

Hence, as in our case, despite that the tumor was resected in approximately $100 \%$, the patient evolution was torpid because of hydrocephalus, so a ventriculoperitoneal shunt was performed, but after 5 days, it became dysfunctional because of mechanical obstruction caused by detritus and hemorrhage, and a new intervention was performed to clean the valve, with later complete recovery of the patient.

About chemotherapy in pediatric patients, some reports say that $14 \%$ of the patients were declared tumor free. ${ }^{[26]}$ Some papers report too that it could be useful for metastatic disease and recurrent disease. ${ }^{[13]}$ On the other hand, radiotherapy is usually used to treat residual tumors by subtotal resection, and some authors say that it should be reserved to treat malignant lesions, recurrent or disseminated, and is not recommended for patients younger than 3 years old. ${ }^{[13]}$

In the past, the tumor survival rate was approximately $50 \%$, but with the improvements in postoperative care, surgical approaches, and neuroimaging, the rate nowadays is close to $100 \% \cdot{ }^{[13]}$ In a meta-analysis, the authors report that survival at 1 year was $90 \%$, 5 years $81 \%$, and 10 years $77 \%{ }^{[12]}$ Surgical removal is the main factor associated with survival and there is not enough evidence yet to recommend other kind of therapy for a patient with choroid plexus papilloma. ${ }^{[12]}$ 


\section{Conclusion}

Choroid plexus papilloma of the fourth ventricle is an infrequent form of presentation of this entity in the pediatric population. Surgical resection is the cornerstone of the management as there is no enough evidence for neoadjuvant therapy.

\section{Declaration of patient consent}

The authors certify that they have obtained all appropriate patient consent forms. In the form the patient(s) has/have given his/her/their consent for his/her/their images and other clinical information to be reported in the journal. The patients understand that their names and initials will not be published and due efforts will be made to conceal their identity, but anonymity cannot be guaranteed.

Financial support and sponsorship

Nil.

\section{Conflicts of interest}

There are no conflicts of interest.

\section{References}

1. Boyd MC, Steinbok P. Choroid plexus tumors: Problems in diagnosis and management. J Neurosurg 1987;66:800-5.

2. Ellenbogen RG, Winston KR, Kupsky WJ. Tumors of the choroid plexus in children. Neurosurgery 1989;25:327-35.

3. Tacconi L, Delfini R, Cantore G. Choroid plexus papillomas: Consideration of a surgical series of 33 cases. Acta Neurochir (Wien) 1996;138:802-10.

4. McEvoy AW, Galloway M, Revesz T, Kitchen ND. Metastatic choroid plexus papilloma: A case report. J Neurooncol 2002;56:241-6.

5. Kumar R, Singh S. Childhood choroid plexus papillomas: Operative complications. Childs Nerv Syst 2005;21:138-43.

6. Mortazavi MM, Griessenauer CJ, Adeeb N, Deep A, Bavarsad Shahripour R, Loukas M, et al. The choroid plexus: A comprehensive review of its history, anatomy, function, histology, embryology, and surgical considerations. Childs Nerv Syst 2014;30:205-14.

7. Karim A, Fowler M, McLaren B, Cardenas R, Patwardhan R, Nanda A, et al. Concomitant choroid plexus papillomas involving the third and fourth ventricles: A case report and review of the literature. Clin Neurol Neurosurg 2006;108:586-9.

8. Carson BS, Weingart JD, Guarnieri M, Fisher PG. Third ventricular choroid plexus papilloma with psychosis. Case report. J Neurosurg 1997;87:103-5.

9. Kroppenstedt SN, Golfinos J, Sonntag VK, Spetzler RF. Pineal region lesion masquerading choroid plexus papilloma: Case report. Surg Neurol 2003;59:124-7.

10. Prasad GL, Mahapatra AK. Case series of choroid plexus papilloma in children at uncommon locations and review of the literature. Surg Neurol Int 2015;6:151.

11. Sarkar C, Sharma MC, Gaikwad S, Sharma C, Singh VP. Choroid plexus papilloma: A clinicopathological study of 23 cases. Surg Neurol 1999;52:37-9.

12. Wolff JE, Sajedi M, Brant R, Coppes MJ, Egeler RM. Choroid plexus tumours. Br J Cancer 2002;87:1086-91.

13. Safaee M, Oh MC, Bloch O, Sun MZ, Kaur G, Auguste KI, et al. Choroid plexus papillomas: Advances in molecular biology and understanding of tumorigenesis. Neuro Oncol 2013;15:255-67.

14. van Swieten JC, Thomeer RT, Vielvoye GJ, Bots GT. Choroid plexus papilloma in the posterior fossa. Surg Neurol 1987;28:129-34.

15. Osborn AG, Salzman KL, Jhaveri MD, Barkovich AJ. Diagnostic Imaging: Brain. $3^{\text {rd }}$ ed., Ch. 137. Elsevier; 2016.

16. Koeller KK, Sandberg GD; Armed Forces Institute of Pathology. From the archives of the AFIP. Cerebral intraventricular neoplasms: Radiologic-pathologic correlation. Radiographics 2002;22:1473-505.

17. Vazquez E, Ball WS Jr., Prenger EC, Castellote A, Crone KR. Magnetic resonance imaging of fourth ventricular choroid plexus neoplasms in childhood. A report of two cases. Pediatr Neurosurg 1991;17:48-52.

18. Li S, Savolaine ER. Imaging of atypical choroid plexus papillomas. Clin Imaging 1996;20:85-90.

19. Due-Tønnessen B, Helseth E, Skullerud K, Lundar T. Choroid plexus tumors in children and young adults: Report of 16 consecutive cases. Childs Nerv Syst 2001;17:252-6.

20. Erman T, Göçer AI, Erdoğan S, Tuna M, Ildan F, Zorludemir S, et al. Choroid plexus papilloma of bilateral lateral ventricle. Acta Neurochir (Wien) 2003;145:139-43.

21. Keating RF, Goodrich JT, Packer RJ. Tumors of the Pediatric Central Nervous System. $1^{\text {st }}$ ed. New York: Thieme; 2001.

22. Levy ML, Goldfarb A, Hyder DJ, Gonzales-Gomez I, Nelson M, Gilles FH, et al. Choroid plexus tumors in children: Significance of stromal invasion. Neurosurgery 2001;48:303-9.

23. Jaiswal AK, Jaiswal S, Sahu RN, Das KB, Jain VK, Behari S, et al. Choroid plexus papilloma in children: Diagnostic and surgical considerations. J Pediatr Neurosci 2009;4:10-6.

24. Pawar SJ, Sharma RR, Mahapatra AK, Lad SD, Musa MM. Choroid plexus papilloma of the posterior third ventricle during infancy \& childhood: Report of two cases with management morbidities. Neurol India 2003;51:379-82.

25. Talacchi A, De Micheli E, Lombardo C, Turazzi S, Bricolo A. Choroid plexus papilloma of the cerebellopontine angle: A twelve patient series. Surg Neurol 1999;51:621-9.

26. Wrede B, Hasselblatt M, Peters O, Thall PF, Kutluk T, Moghrabi A, et al. Atypical choroid plexus papilloma: Clinical experience in the CPT-SIOP-2000 study. J Neurooncol 2009;95:383-92. 